\section{p-ISSN 2476-9886 \\ e-ISSN 2477-0302 \\ J.Edu}

Volume 5 Nomor 2, 2019, HIm 71-75

\section{Jurnal EDUCATIO}

Jurnal Pendidikan Indonesia
Akses Online :

http://jurnal.iicet.org

Dipublikasikan oleh :

Indonesian Institute for Counseling, Education and Therapy (IICET)

Info Artikel:

Diterima: 07/09/2019

\title{
The effect of digital literacy to internet addiction
}

\author{
Raymond Frans Deonisius ${ }^{1}$, Ika Lestari ${ }^{2}$, Sarkadi $^{3}$ \\ ${ }^{123}$ Universitas Negeri Jakarta
}

\begin{abstract}
The purpose of this study was to investigate the effect of digital literacy to internet addiction. For this purposed, we conducted a survey from 347 participants of middle school students at Menteng sub-district, Central Jakarta. This study was used a simple regression equation model to evaluate the structural model. The result showed that digital literacy positively significant affected internet addiction. Digital literacy simultaneously had a positive significant effect to internet addiction.
\end{abstract}

Keywords: digital literacy, internet addiction, middle school

This is an open access article distributed under the Creative Commons Attribution License, which permits unrestricted use,
distribution, and reproduction in any medium, provided the original work is properly cited. C2019 by author.

\section{PENDAHULUAN}

Lebih dari 50\% populasi dunia saat ini merupakan pengguna internet aktif (Insights, Internet, Media, Use, \& The, 2018). Selanjutnya, berdasarkan survey yang dilakukan di Indonesia pada tahun 2017, menunjukkan bahwa sebesar 54,68\% penduduk Indonesia tahun 2017 merupakan pengguna internet aktif (APJII, 2017) dan meningkat pada tahun 2018 menjadi 64,8\% (APJII, 2018). Fenomena tersebut membuat pemerintah Indonesia dalam berita harian kompas.com menyatakan bahwa akan berupaya meningkatkan program literasi digital. Literasi digital merupakan sebuah kemampuan menggunakan teknologi untuk mengolah informasi mulai dari mencari informasi, mengkritisi sebuah informasi, mengevaluasi sebuah informasi, membagikan informasi, hingga membentuk sebuah konsep pemikiran baru untuk mengembangkan kemampuan pemecahan masalah (Chan \& Chiu, 2017; Hsu, Wenting, \& Hughes, 2018; Noh, 2017; Zhao, Kynäshlahti, \& Sintonen, 2018). Tidak dapat dipungkiri bahwa kehadiran internet dan kemajuan teknologi serta peningkatan program literasi digital dapat memberikan banyak manfaat namun juga dapat memberikan dampak negatif.

Dampak positif dari peningkatan program literasi digital yaitu seseorang menjadi mampu mengembangkan seluruh kemampuan dalam mengolah informasi yang didapat dari internet (Chan \& Chiu, 2017; Hsu et al., 2018; Kimbell-Lopez, Cummins, \& Manning, 2016; Noh, 2017; Zhao et al., 2018). Selain mempunyai dampak positif, ternyata literasi yang memanfaatkan teknologi digital juga mempunyai dampak negatif. Pemahaman literasi digital yang buruk tidak dapat meningkatkan etika dan tanggung jawab siswa, siswa lebih memilih untuk memposting di media sosial yang cenderung menghina orang lain dengan menggunakan bahasa yang kurang sopan (Hsu et al., 2018; Pratiwi, 2017). Penggunaan internet yang problematis dalam pemanfaatan media digital membuat anak semakin menghabiskan waktu untuk online. 
Penggunaan internet yang problematis dikatakan sebagai kecanduan internet (Tsitsika et al., 2011). Kecanduan internet tersebut disebabkan karena penggunaan internet yang berlebihan pada aplikasi-aplikasi internet (Arslan \& Kiper, 2018; Dufour et al., 2016; Gómez, Rial, Braña, Golpe, \& Varela, 2017). Kecanduan internet menjadi masalah yang sering muncul dikalangan remaja, terutama pada jenjang Sekolah Menengah Pertama. Beberapa kajian dari berbagai negara seperti Jordania, Hong Kong, China, Yunani, dan Belanda menyatakan bahwa remaja yang berada pada jenjang pendidikan SMP teridentifikasi mengalami kecanduan internet (Jiang \& Leung, 2012; Kuss, Van Rooij, Shorter, Griffiths, \& Van De Mheen, 2013; Leung \& Lee, 2012b; Malak, Khalifeh, \& Shuhaiber, 2017; Tsitsika et al., 2011). Kajian-kajian tersebut mengindikasikan bahwa penggunaan internet yang tidak tepat oleh siswa SMP dapat menyebabkan kecanduan internet.

Berdasar pada asumsi tersebut, maka dibuatlah hipotesis penelitian yang akan digunakan untuk mengivestigasikan pengaruh digital literacy terhadap kecanduan internet. Adapun hipotesis pada penelitian ini yaitu digital literacy memiliki pengaruh positif dan siginifikan terhadap kecenderungan kecanduan internet.

\section{METODE}

Penelitian dilakukan pada siswa SMP se-Kecamatan Menteng, Jakarta Pusat yang terdiri dari 2617 orang. Sampel diambil menggunakan rumus slovin dengan galat 0.01 sehingga didapat jumlah sampel 347 orang dengan proporsi seimbang dari setiap tingkatan kelas. Data dihimpun dari kuesioner online yang disebar pada responden penelitian menggunakan google form. Responden dapat mengakses kuesioner dari tautan yang telah diberikan melalui group whatsapp. Data pribadi responden terjamin karena responden tidak diwajibkan mencantumkan nama karena pihak sekolah hanya meminta hasil penelitian secara keseluruhan.

Instrumen diturunkan dari dimensi-dimensi pembentuk variabel digital literacy dan kecanduan internet. Instrumen digital literacy dikembangkan dari empat dimensi yaitu internet searching, hypertextual navigation, content evaluation, dan knowledge assembly (Lankshear \& Knobel, 2006). Instrument terdiri dari 31 butir menggunakan skala likert yang diujikan, dan terdapat 18 butir valid sedangkan 13 butir gugur karena memiliki thitung lebih kecil dari ttabel $(\alpha=0.05, \mathrm{df}=28)$ yaitu 1,701 . Nilai koefisien cronbach's alpha instrument digital literacy adalah 0.836, yang artinya instrumen digital literacy reliabel. Instrument kecanduan internet disusun berdasarkan tujuh dimensi yaitu tolerance, withdrawal symptoms, lost of control, preoccupation, conflict, coping, lying about involvement (Meerkerk, Van Den Eijnden, Vermulst, \& Garretsen, 2009). Insrumen terdiri dari 33 butir, terdapat 11 butir gugur sehingga tersisa 22 butir instrumen kecanduan internet. Nilai koefisien cronbach's alpha menghasilkan 0.843 yang artinya instrumen kecanduan internet reliabel dan dapat digunakan untuk mengukur kecenderungan kecanduan internet dari responden.

Analisis model regresi sederhana dipilih sebagai analisis yang tepat untuk menguji model dan metode yang dapat menjelaskan pengaruh dari variabel digital literacy terhadap kecanduan internet. Data analisis menggunakan software SPSS 20. Tahap pertama dalam analisis adalah menyiapkan data, data yang dianalisis diuji asumsi terlebih dahulu. Uji asumsi yang akan dilakukan diantaranya adalah uji normalitas, uji linieritas, dan uji multikolinieritas.

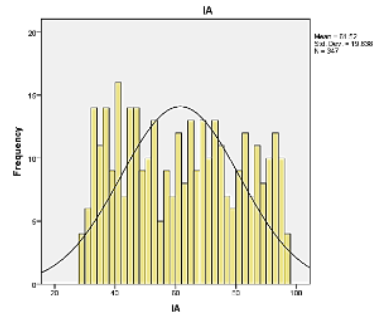

Gambar 1. Grafik Uji Normalitas Kecanduan Internet

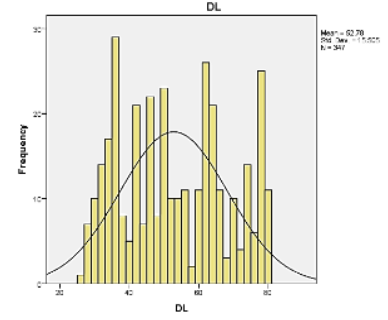

Gambar 2. Grafik Uji Normalitas Digital Literacy

Pada grafik uji normalitas variabel kecanduan internet (gambar1) dan uji normalitas digital literacy (gambar 2) terlihat bahwa sebaran data penelitian membentuk kurva normal. Data penelitian dikatakan normal jika memiliki nilai signifikansi lebih dari 0.05. Hasil uji normalitas menunjukkan nilai signifikansi untuk variabel kecanduan internet adalah 0.12 dan digital literacy bernilai 0.13 . Dengan demikian, dapat disimpulkan bahwa data penelitian berdistribusi normal. Selanjutnya adalah hasil uji linieritas terangkum dalam tabel 1. 
Tabel 1. Rekaptulasi Hasil Uji Linieritas

\begin{tabular}{|c|c|c|c|c|c|c|}
\hline & & Sum of Squares & df & $\begin{array}{c}\text { Mean } \\
\text { Square }\end{array}$ & $\mathbf{F}$ & Sig. \\
\hline & (Combined) & 22812.705 & 51 & 447.308 & 1.193 & 0.187 \\
\hline Between Groups & Linierity & 4481.342 & 1 & 4481.342 & 11.951 & 0.001 \\
\hline $\mathbf{I A} * \mathbf{D L}$ & $\begin{array}{r}\text { Deviation from } \\
\text { Linierity }\end{array}$ & 18331.363 & 50 & 366.627 & 0.978 & 0.521 \\
\hline Within Groups & & 110617.837 & 295 & 374.976 & & \\
\hline Total & & 133430.542 & 346 & & & \\
\hline
\end{tabular}

Hasil uji linieritas berdasarkan output tabel 1, diperoleh nilai deviation from linierity signifikan adalah 0.521 lebih besar dari 0.05. Selanjutnya, nilai $F$ hitung adalah $0.978<1.39(\mathrm{df1}=50, \mathrm{df} 2=295, \alpha=0.05)$. Maka, berdasarkan uji siginifikansi (Sig.) dan uji F, dapat disimpulkan bawah ada hubungan linier secara signifikan antara variabel digital literacy (X) dengan variabel kecanduan internet (Y). Selanjutnya, hasil uji multikolinieritas menunjukan bahwa nilai tolerance $1,000>0.10$ dan nilai VIF 1,000<10 yang artinya bahwa tidak terjadi kolinieritas antar variabel sehingga dapat dilanjutkan kedalam tahapan pengujian selanjutnya.

\section{HASIL}

Tahap analisis pertama adalah melakukan pengecekan terhadap persamaan struktural dan melakukan analisis regresi linier sederhana. Hasil analisis regresi linier sederhana variabel digital literacy (X) terhadap kecanduan internet (Y) terangkum dalam Tabel 2.

Tabel 2. Rekaptulasi Hasil Uji Regresi Sederhana

\begin{tabular}{|c|c|c|c|c|c|}
\hline \multirow[t]{2}{*}{ Model } & \multicolumn{2}{|c|}{ Unstandardized Coeficients } & \multirow{2}{*}{$\begin{array}{c}\begin{array}{c}\text { Standardized } \\
\text { Coeficients }\end{array} \\
\text { Beta }\end{array}$} & \multirow[t]{2}{*}{$\mathrm{t}$} & \multirow[t]{2}{*}{ Sig. } \\
\hline & B & Std. Error & & & \\
\hline 1 (Constant) & 49.272 & 3.687 & & 13.362 & 0.000 \\
\hline DL & 0.232 & 0.067 & 0.183 & 3.463 & 0.001 \\
\hline
\end{tabular}

Berdasarkan hasil uji regresi sederhana, didapat bahwa persamaan structural regresinya adalah Ý $=49.272+$ $0.232 X$. Pengukuran selanjutnya adalah melihat hasil uji signifikansi variabel digital literacy terhadap kecanduan internet. Hasil uji signifikansi menunjukkan $0.00<0.05$, yang artinya terjadi pengaruh yang signifikan dari variabel digital literacy terhadap kecanduan internet. Nilai Beta pada tabel 1 menunjukan 0.183, yang artinya masih jauh dari nilai 1 yang berarti mempunyai pengaruh yang sempurna.

Tabel 4. Rekaptulasi Hasil Uji Kontribusi Regresi

\begin{tabular}{|c|c|c|c|c|}
\hline Model & $\mathrm{R}$ & R Square & Adjusted R square & $\begin{array}{l}\text { Std. Error of the } \\
\text { Estimate }\end{array}$ \\
\hline 1 & $0.183^{\mathrm{a}}$ & 0.034 & 0.031 & 19.3333 \\
\hline
\end{tabular}

Pengaruh yang diberikan variabel digital literacy terhadap kecanduan internet berdasarkan nilai $\mathrm{R}$ square sebesar 0.034 (bernilai positif). Kontribusi variabel digital literacy terhadap kecanduan internet sebesar 0.034, artinya digital literacy berkontribusi sebesar $3.4 \%$ terhadap kecanduan internet.

\section{PEMBAHASAN}

Setelah melakukan uji regresi linier sederhana, diketahui bahwa model persamaan regresinya menunjukan hasil yang baik. Pengujian selanjutnya adalah melakukan uji model persamaan regresi. Pengujian model persamaan regresi ini dilakukan untuk menguji hipotesis penelitian yang diajukan. Dari hasil uji regresi linier sederhana didapatkan persamaan regresi yaitu $\widehat{\mathbf{Y}}=49,272+0,232 \mathrm{X}$. Berdasar nilai konstanta sebesar 49,272 artinya setiap variabel digital literacy $(\mathrm{X})$ nilainya adalah 0 , maka variabel kecanduan internet $(\mathrm{Y})$ nilainya yaitu sebesar 49,504. Selanjutnya, koefisien regresi variabel digital literacy (X) sebesar 0,232 yang artinya jika nilai 
variabel digital literacy mengalami kenaikan 1 satuan, maka variabel kecanduan internet (Y) akan mengalami peningkatan sebesar 49,504 satuan. Koefisien bernilai positif artinya terjadi hubungan positif antara digital literacy dengan kecanduan internet, semakin naik tingkat digital literacy semakin meningkatkan kecanduan internet. Dengan demikian, hipotesis terdukung. Hasil ini membuktikan sebuah kajian yang dilakukan di Hong Kong yang menyatakan dalam penelitiannya bahwa digital literacy merupakan predictor yang muncul secara psoitif dan signifikan dari gejala-gejala kecanduan internet (Leung \& Lee, 2012a). Perkembangan zaman dan kemajuan teknologi membuat siswa SMP atau remaja saat ini menjadi keharusan untuk mengenal dan mendalami teknologi yang berbasis internet sehingga tidak terhindarkan semakin banyak remaja yang mengalami kecenderungan kecanduan internet.

Temuan selanjutnya dari hasil uji regresi di atas adalah nilai Beta (B) sebesar 0,183 atau tidak mendekati nilai 1. Nilai Beta (ß) tersebut dapat diartikan bahwa digital literacy merupakan prediktor kurang sempurna yang memberikan pengaruh besar terhadap kecanduan internet. Hasil ini juga didukung dengan nilai R square sebesar 0,034 atau 3,4\%, yang artinya hanya sebesar 3,4\% saja pengaruh yang diberikan variabel digital literacy terhadap kecanduan internet. Maka dapat disimpulkan 96,6\% (100\%-3,4\%) merupakan faktor atau prediktor lain yang memengaruhi kecanduan internet. Depresi, kegelisahan, kesepian, dan stress akademik adalah prediktorprediktor positif dan signifikan yang memengaruhi kacanduan internet (Banjanin, Banjanin, Dimitrijevic, \& Pantic, 2015; Bilal, 2018; Eijnden, 2014; Faculty, 2010; Iskender, 2014; Jun \& Choi, 2015; Kim et al., 2006; Leung \& Lee, 2012b; Ostovar, Allahyar, \& Aminpoor, 2016; Scimeca et al., 2014; Yang, Sun, Zhang, Sun, \& $\mathrm{Wu}, 2014$; Younes et al., 2016).

\section{KESIMPULAN}

Berdasarkan hasil peelitian yang telah dilakukan, dapat disimpulkan bahwa secara parsial digital literacy mempunyai pengaruh positif dan signifikan terhadap kecenderungan kecanduan internet. Hasil uji regresi membuktikan bahwa digital literacy secara simultan berpengaruh positif dan signifikan terhadap kecenderungan kecanduan internet. Kecenderungan kecanduan internet yang dipengaruhi oleh digital literacy adalah sebesar $3,4 \%$. Keterbatasan dari penelitian ini adalah data hanya diamnbil dari satu jenjang pendidikan saja yaitu SMP. Pada penelitian selanjutnya sampel penelitian dapat diperluas dengan mengambil data dari jenjang SD sampai pada SMA. Penelitian selanjutnya pun dapat dikembangkan dengan mengeksplorasi predictor baru lainnya yang memengaruhi kecanduan internet di kalangan sekolah formal.

\section{REFERENSI}

APJII. (2017). Penetrasi \& Perilaku Pengguna Internet Indonesia 2017. Asosiasi Penyelenggara Jasa Internet Indonesia, 1-39.

APJII, 2018. (2018). Penetrasi \& profil perilaku pengguna internet indonesia.

Arslan, N., \& Kiper, A. (2018). Self-Disclosure and Internet Addiction. Malaysian Online Journal of Educational Technology, 6(1), 56-63. Retrieved http://ezproxy.lib.uconn.edu/login?url=https://search.ebscohost.com/login.aspx?direct=true \&db=eric\&AN $=$ EJ1165449\&site=ehost-live

Banjanin, N., Banjanin, N., Dimitrijevic, I., \& Pantic, I. (2015). Relationship between internet use and depression: Focus on physiological mood oscillations, social networking and online addictive behavior. Computers in Human Behavior, 43, 308-312. https://doi.org/10.1016/j.chb.2014.11.013

Bilal, M. (2018). University of Sargodha The Relationship between Internet Addiction and Anxiety among students of University of Sargodha, (May).

Chan, B. S. K., \& Chiu, T. K. F. (2017). Digital Literacy Learning In Higher Education Through Digital Storytelling Approach. Journal of International Education Research, 13(1), 1-16. Retrieved from http://files.eric.ed.gov/fulltext/EJ1144564.pdf

Dufour, M., Brunelle, N., Tremblay, J., Leclerc, D., Cousineau, M. M., Khazaal, Y., ... Berbiche, D. (2016). Gender Difference in Internet Use and Internet Problems among Quebec High School Students. Canadian Journal of Psychiatry, 61(10), 663-668. https://doi.org/10.1177/0706743716640755

Eijnden, V. Den. (2014). Computers in Human Behavior Depression, loneliness and Internet addiction : How important is low, 34, 284-290. https://doi.org/10.1016/j.chb.2014.02.009

Faculty, E. (2010). RELATION BETWEEN DEPRESSION , LONELINESS , SELF-ESTEEM AND INTERNET ADDICTION, (2000), 283-290.

Gómez, P., Rial, A., Braña, T., Golpe, S., \& Varela, J. (2017). Screening of Problematic Internet Use Among Spanish Adolescents: Prevalence and Related Variables. Cyberpsychology, Behavior, and Social 
Networking, 20(4), 259-267. https://doi.org/10.1089/cyber.2016.0262

Hsu, H.-P., Wenting, Z., \& Hughes, J. E. (2018). Developing Elementary Students' Digital Literacy Through Augmented Reality Creation: Insights From a Longitudinal Analysis of Questionnaires, Interviews, and Projects. Journal of Educational Computing Research. https://doi.org/10.1177/0735633118794515

Insights, E., Internet, I., Media, S., Use, E., \& The, A. (2018). DIGITAL IN 2018.

Iskender, M. (2014). Internet Addiction and Depression, Anxiety and Stress, (January 2011).

Jiang, Q., \& Leung, L. (2012). Effects of individual differences, awareness-knowledge, and acceptance of internet addiction as a health risk on willingness to change internet habits. Social Science Computer Review, 30(2), 170-183. https://doi.org/10.1177/0894439311398440

Jun, S., \& Choi, E. (2015). Computers in Human Behavior Academic stress and Internet addiction from general strain theory framework. COMPUTERS IN HUMAN BEHAVIOR, 49, 282-287. https://doi.org/10.1016/j.chb.2015.03.001

Kim, K., Ryu, E., Chon, M., Yeun, E., Choi, S., Seo, J., \& Nam, B. (2006). Internet addiction in Korean adolescents and its relation to depression and suicidal ideation: A questionnaire survey, 43, 185-192. https://doi.org/10.1016/j.ijnurstu.2005.02.005

Kimbell-Lopez, K., Cummins, C., \& Manning, E. (2016). Developing Digital Literacy in the Middle School Classroom. Computers in the Schools, 33(4), 211-226. https://doi.org/10.1080/07380569.2016.1249731

Kuss, D. J., Van Rooij, A. J., Shorter, G. W., Griffiths, M. D., \& Van De Mheen, D. (2013). Internet addiction in adolescents: Prevalence and risk factors. Computers in Human Behavior, 29(5), 1987-1996. https://doi.org/10.1016/j.chb.2013.04.002

Lankshear, C., \& Knobel, M. (2006). Digital literacy and digital literacies. Digital Kompetanse, 1, 12-24. https://doi.org/10.1108/EL-05-2015-0076

Leung, L., \& Lee, P. S. N. (2012a). Impact of Internet Literacy, Internet Addiction Symptoms, and Internet Activities on Academic Performance. Social Science Computer Review, 30(4), 403-418. https://doi.org/10.1177/0894439311435217

Leung, L., \& Lee, P. S. N. (2012b). The influences of information literacy, internet addiction and parenting styles on internet risks. New Media and Society, 14(1), 117-136. https://doi.org/10.1177/1461444811410406

Malak, M. Z., Khalifeh, A. H., \& Shuhaiber, A. H. (2017). Prevalence of Internet Addiction and Associated Risk Factors in Jordanian School Students. Computers in Human Behavior. Elsevier B.V. https://doi.org/10.1016/j.chb.2017.01.011

Meerkerk, G.-J., Van Den Eijnden, R. J. J. M., Vermulst, A. A., \& Garretsen, H. F. L. (2009). The Compulsive Internet Use Scale (CIUS): Some Psychometric Properties. CyberPsychology \& Behavior, 12(1), 1-6. https://doi.org/10.1089/cpb.2008.0181

Noh, Y. (2017). A study on the effect of digital literacy on information use behavior. Journal of Librarianship and Information Science, 49(1), 26-56. https://doi.org/10.1177/0961000615624527

Ostovar, S., Allahyar, N., \& Aminpoor, H. (2016). Internet Addiction and its Psychosocial Risks ( Depression, Anxiety, Stress and Loneliness ) among Iranian Adolescents and Young Adults : A Structural Equation Model in a Cross-Sectional Study. https://doi.org/10.1007/s11469-015-9628-0

Pratiwi, N. (2017). Pengaruh Literasi Digital terhadap Psikologis Anak dan Remaja, 11-24.

Scimeca, G., Bruno, A., Cava, L., Pandolfo, G., Rosaria, M., Muscatello, A., \& Zoccali, R. (2014). The Relationship between Alexithymia, Anxiety, Depression, and Internet Addiction Severity in a Sample of Italian High School Students, 2014.

Tsitsika, A., Critselis, E., Louizou, A., Janikian, M., Freskou, A., Marangou, E., ... Kafetzis, D. A. (2011). Determinants of internet addiction among adolescents: A case-control study. TheScientificWorldJournal, 11, 866-874. https://doi.org/10.1100/tsw.2011.85

Yang, L., Sun, L., Zhang, Z., Sun, Y., \& Wu, H. (2014). Internet addiction , adolescent depression , and the mediating role of life events: Finding from a sample of Chinese adolescents, (81202224). https://doi.org/10.1002/ijop.12063

Younes, F., Halawi, G., Jabbour, H., Osta, N. El, Karam, L., Hajj, A., \& Khabbaz, L. R. (2016). Internet Addiction and Relationships with Insomnia, Anxiety, Depression, Stress and Self-Esteem in University Students : A Cross- Sectional Designed Study, (Dass 21), 1-13. https://doi.org/10.1371/journal.pone.0161126

Zhao, P., Kynäshlahti, H., \& Sintonen, S. (2018). A qualitative analysis of the digital literacy of arts education teachers in Chinese junior high and high schools. Journal of Librarianship and Information Science, 50(1), 77-87. https://doi.org/10.1177/0961000616658341 